\title{
Sonoluminescence: When bubbles glow
}

\author{
Sascha Hilgenfeldt and Detlef Lohse*
}

In single-bubble sonoluminescence, an ultrasound-driven microbubble undergoes violent oscillations and converts part of the energy of the sound field into visible light. Since its discovery ten years ago, a consistent theory of the dynamics and stability of the bubble has been developed. The approach includes the dissociation of molecular gases inside the collapsing bubble to explain striking differences in experiments with various molecular and noble gases. A natural extension of the theory incorporates the light emission itself, identifying its mechanism as thermal bremsstrahlung from the optically thin (transparent) bubble. A direct and systematic comparison of the results of the theory with experiment shows good agreement in all characteristic features.

WHEN Felipe Gaitan was working on his $\mathrm{PhD}$ at the University of Mississippi in 1990, he hoped for new insights into the dynamics of a single, ultrasonically driven bubble. He was thrilled to discover that he could make the bubble emit a steady glow of bluish light. This phenomenon is now known as (single bubble) sonoluminescence (SL) ${ }^{1-3}$. Converting sound into light is not only a fascinating feat, but is remarkable for the physicist as well: the energy density in the emitted photons is about 12 orders of magnitude greater than that in the driving sound field!

An additional appeal comes from the simplicity of the experimental set-up (Figure 1), whose main component is a flask filled with partially degassed water (the gas concentration is smaller than the saturation concentration). A single bubble is injected into the flask; a standing ultrasound wave (with typical frequencies of $20-40 \mathrm{kHz}$ and pressure amplitudes of 1.2-1.5 atm) traps the bubble at the centre of the vessel and at the same time excites it to highly nonlinear radial oscillations. The bubble collapses very violently once per driving cycle and concentrates the energy sufficiently to allow for the emission of a very brief pulse of light. Even though the bubble is only a few micrometers across, its light is visible to the naked eye.

SL immediately became the target of the efforts of many research groups, but several years after Gaitan's discovery the mechanism of light emission was still unknown, and a number of other unresolved puzzles had appeared. These included the extreme stability of the phenomenon (over hours or days) in a very narrow range of driving pressures or the increase of the light intensity with decreasing water temperature. A series of experiments with different gas mixtures revealed perhaps the most astonishing result: a tiny amount of a noble gas (like $1 \%$ argon contained in air)

Sascha Hilgenfeldt is in the DEAS, Harvard University, 29 Oxford St, Cambridge, MA 02138, USA and Detlef Lohse is in the University of Twente, Department of Applied Physics, P.O. Box 217, 7500 AE Enschede, The Netherlands.

*For correspondence. (e-mail: D.Lohse@tn.utwente.nl) is necessary for the above-mentioned stability - without it the bubbles do not live longer than a couple of minutes.

Almost all of these open questions have been answered satisfactorily in the past few years, and the increased understanding of SL bubbles has finally led to a plausible model for the light emission, too. The starting point for the work in our group was the stability of the bubbles, for which ground-breaking work was done by Andrea

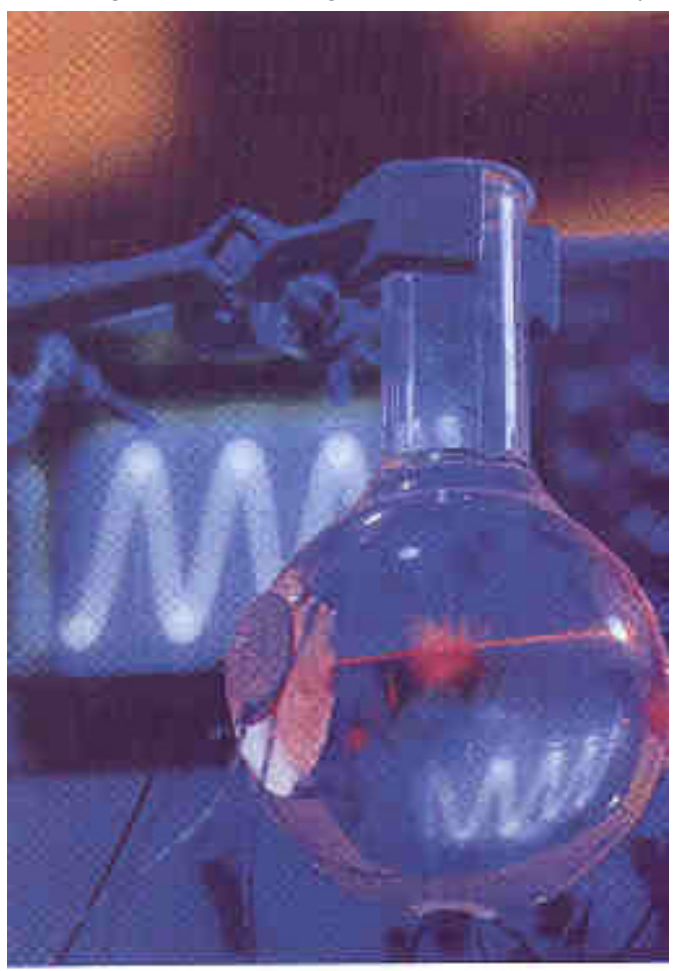

Figure 1. Photograph showing a water-filled flask used in the single-bubble SL experiment, with a glowing bubble at its center. The annular object on the flask wall is one of the two piezoelectric transducers which generate the sound field. 
Prosperetti $^{4-6}$ and also by many others ${ }^{7-11}$.

It soon became clear that the bubble can only be stable if (i) perturbations of its spherical shape stay small ${ }^{12}$, and (ii) the gas content of the bubble (its mass) stays constant in time and is not changed through diffusive mass exchange with the dissolved gas in the water ${ }^{13}$. The validity or violation of both criteria can be checked directly from the dynamics of the bubble oscillation. As a result, the shape stability condition (i) gives upper bounds for bubble mass and driving pressure: if the bubble contains too much gas or if it is driven too strongly, it becomes shape unstable and finally fragments into many microbubbles. The diffusive stability condition (ii) singles out one specific gas content for a bubble in stable diffusive equilibrium with its surroundings (at given gas concentration and driving pressure). Obviously, both conditions (i) and (ii) can be fulfilled simultaneously only in a certain domain of parameter space. Calculating this region ${ }^{13}$ gives excellent agreement with experiments that use pure argon or other pure noble gases, where very strong degassing to about $0.2-0.4 \%$ of saturation is necessary for stable bubbles.

Until recently, however, there was a huge discrepancy between the theoretical predictions for air (which are almost identical to those for pure noble gases) and the observed stability of SL bubbles at $20-40 \%$ of saturation for air, i.e. for about 100 times greater concentration of dissolved gas. We found a very simple rationalization for this phenomenon $^{14}$ : at the high temperatures inside the collapsing bubble all molecular gases (oxygen, nitrogen) in the air dissociate, and the resulting radicals form products that dissolve in the surrounding water. The only constituent of air which cannot dissociate is argon, and it is all that remains of the air bubble. As about one part in 100 of air is argon, the actual relevant concentration of dissolved gas is 100-fold smaller than the total air concentration, and is thus again in outstanding agreement with theory. These predictions have meanwhile been confirmed by quantitative experiments conducted by Robert Apfel and his group at Yale ${ }^{15}$. This 'burning off' of molecular gases also explains why a small amount of noble gas is necessary to ensure stable SL.

As material parameters are changed, the boundaries for bubble stability shift, too. This offers a natural explanation for the increase in light intensity upon cooling of the water $^{16}$ : the stability diagrams show that the largest stable bubbles can also be driven at the highest pressure amplitudes. Therefore, they show the most violent collapses and emit the most intense light. When the water is cooled, the parameter regime of stable SL widens because (among other effects) the viscosity of water and the solubility of the gas increase. Thus, larger bubbles can be stable at higher drivings and emit light pulses of considerably higher intensity. Similar effects might be achieved by using nonaqueous fluids instead of water, exploiting their different viscosities, surface tensions, etc.

The picture of light emission itself, the spectacular feature of sonoluminescing bubbles, has also cleared up a lot recently. Bruno Gompf, Wolfgang Eisenmenger and their collaborators at the University of Stuttgart ${ }^{17,18}$ obtained the first time-resolved measurement of the light pulse, using single-photon correlation. Depending on gas concentration and driving pressure amplitude, the temporal width of the pulse was found to be $60-300$ ps. These results improved and corrected earlier estimates of US-based groups ${ }^{3,19}$ which suggested much smaller pulse widths. Another important result obtained at Stuttgart is the near independence of the pulse width on the wavelength of the light (the pulse is as long in the red part of the spectrum as in the ultraviolet). The observations contradict the most simple model one could postulate for SL light emission: if SL was thermal black body radiation from the hot bubble, the pulse widths should be larger still, and should vary with wavelength by as much as a factor of two.

It turned out ${ }^{20}$, though, that the black body model needs but a small modification, which follows directly from the physical properties of the gas in the bubble: to emit black body radiation, the bubble has to be black, i.e. an ideal absorber for all wavelengths. The calculated mean free path of photons in the gas of the collapsed bubble, however, is always larger than the bubble radius, so that the bubble is transparent for all the photons it emits. Thus, our picture of SL light emission is the following ${ }^{21}$ : (1) The violent collapse of the bubble heats the gas to about $20,000 \mathrm{~K}$ (just like the air in a bicycle tyre, only at a much more extreme compression). (2) At these temperatures a small fraction of noble gas atoms are ionized and release free electrons into the gas. (3) Bremsstrahlung of the free electrons in the field of the ions and neutral atoms as well as radiative recombination are sources of photon emission in the weakly ionized gas. The photons are not reabsorbed in the transparent gas, and can be observed directly for wavelengths $>200 \mathrm{~nm}$ (smaller wavelengths are absorbed in the surrounding water). (4) After about $100 \mathrm{ps}$ the temperature in the bubble begins to fall again. The ionization shows an extremely sensitive dependence on temperature, and thus drops precipitously. Therefore, photon emission at all wavelengths ceases simultaneously.

This approach explains both the typical width of SL pulses and their equal length in the red and UV spectral regimes. The spectrum of emitted photons in this case carries information about the light emitting processes, unlike a pure black body radiation, which has a universal spectrum independent of the microscopic emission processes. Our model ${ }^{21}$, which does not contain any adjustable parameters, is indeed able to reproduce not only the observed photon numbers and widths of SL pulses, but also their spectra satisfactorily.

All above-mentioned calculations are computationally relatively inexpensive, just as those for bubble shape stability and diffusive stability. Therefore, we can obtain results for many parameter combinations in the parameter space of SL, and can for the first time compare the results 


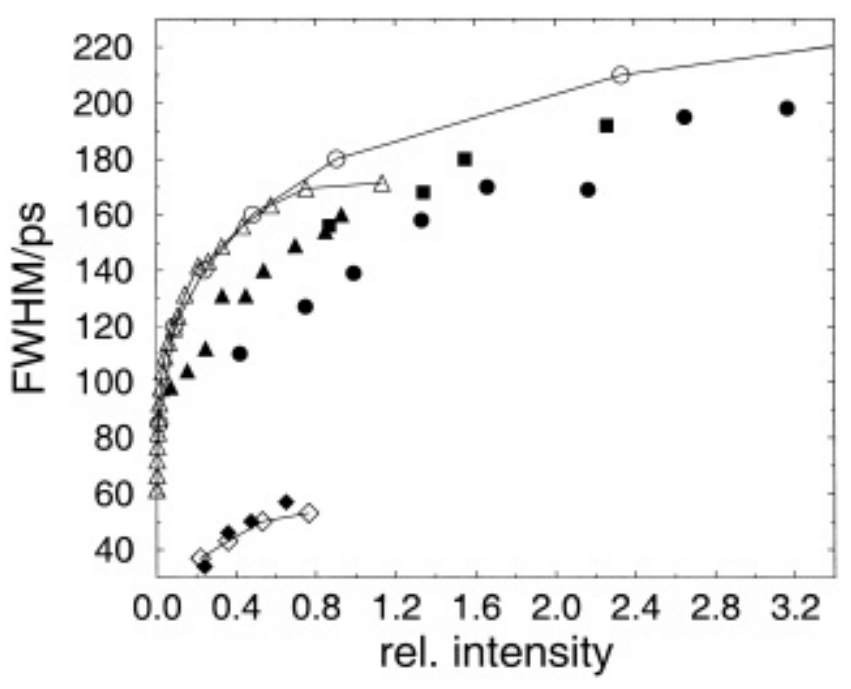

Figure 2. Comparison of measured SL pulse widths and intensities (filled symbols) and predictions from the theory outlined here (open symbols). Data are for xenon (circles) and argon (triangles) at a gas concentration of $0.4 \%$ saturation, and for air (diamonds) at $3 \%$, for which the theoretical calculations used argon at $0.03 \%$ because of the 'burning off' of oxygen and nitrogen in air. The driving frequency is $34 \mathrm{kHz}$ in all cases.

directly to whole sets of reliable experimental data, see Figure 2. Here we show the width of the SL light pulse as a function of its intensity, computed theoretically and compared to various experimental results for different concentrations of dissolved argon, xenon, and air. The gas concentration is the same for all points in one data set, while the driving pressure is varied. The longest and most intense pulses represent the largest drivings. The theoretical predictions of our model, based only on experimental parameters and material constants (no fit parameters!) agree well with the data, capturing the qualitative trend in all cases and the quantitative value for most data points ${ }^{21,22}$.

Note that a comparison like this tests all the salient features of the model: to calculate the light emission, one has to know the gas content of the bubble that is stable at a given driving pressure, necessitating a bubble stability computation. The dissolved gas concentration has to be modified for air as only argon remains in the bubble - for the case in Figure 2, where the experiment used air degassed to $3 \%$ of saturation the computation must be done for argon at $0.03 \%$. Finally, the mutual dependence of pulse widths and intensities probes our physical concept of SL light emission. The good agreement with experiment provides strong support for the validity of our basic assumptions. We stress that our theoretical description makes use of nothing but well-known physical principles. SL is, without doubt, one of the most fascinating phenomena of physics in the past decade - its main features could now be explained using quite old-fashioned physics.

While the theoretical concept of SL becomes more and more complete, practical applications for the newly-acquired knowledge begin to emerge. With the dissociation and ionization reactions in its interior, a SL bubble is a microlaboratory for high temperature chemistry. Perhaps it will be possible to control the reaction by adjusting external parameters like driving pressure or water temperature. Ultrasonically-driven clouds of many bubbles are already in use as 'catalysts' for chemical reactions (sonochemistry) $)^{23,24}$.

Medicine offers another application for micrometer-sized bubbles: In ultrasound diagnostics, they are ideal tracers or contrast agents because of their huge scattering crosssections for diagnostic ultrasound ${ }^{25,26}$. With our present understanding of bubble dynamics, largely due to SL research, a deliberate 'design' of contrast agents is now possible.

Without Gaitan's initial experiments, the perspectives in the above-mentioned applications would probably be less bright. SL, with its multitude of phenomena from diverse fields of physics, engineering, and chemistry, thus highlights the importance of fundamental research as well as the necessity for interaction between the disciplines.

1. Gaitan, D. F., Ph D thesis, University of Mississippi, 1990.

2. Crum, L. A., Phys. Today, 1994, 47, 22.

3. Barber, B. P. et al., Phys. Rep., 1997, 281, 65.

4. Prosperetti, A., Q. Appl. Math., 1977, 34, 339.

5. Plesset, M. and Prosperetti, A., Annu. Rev. Fluid Mech., 1977, 9, 145.

6. Prosperetti, A., J. Fluid Mech., 1991, 222, 587.

7. Eller, A., J. Acoust. Soc. Am., 1969, 46, 1246.

8. Eller, A. and Crum, L., J. Acoust. Soc. Am. Suppl., 1970, 47, 762 .

9. Fyrillas, M. M. and Szeri, A. J., J. Fluid Mech., 1994, 277, 381

10. Brennen, C. E., Cavitation and Bubble Dynamics, Oxford University Press, Oxford, 1995.

11. Leighton, T. G., The Acoustic Bubble, Academic Press, London, 1996.

12. Brenner, M., Lohse, D. and Dupont, T., Phys. Rev. Lett., 1995, 75, 954.

13. Hilgenfeldt, S., Lohse, D. and Brenner, M. P., Phys. Fluids, 1996, 8, 2808.

14. Lohse, D. et al., Phys. Rev. Lett., 1997, 78, 1359.

15. Ketterling, J. A. and Apfel, R. E., Phys. Rev. Lett., 1998, 81, 4991.

16. Hilgenfeldt, S., Lohse, D. and Moss, W., Phys. Rev. Lett., 1998, 80, 1332 .

17. Gompf, B. et al., Phys. Rev. Lett., 1997, 79, 1405.

18. Pecha, R., Gompf, B., Nick, G. and Eisenmenger, W., Phys. Rev. Lett., 1998, 81, 717.

19. Moran, M. J. et al., Phys. Res., 1995, B96, 651.

20. Moss, W., Clarke, D. and Young, D., Science, 1997, 276, 1398.

21. Hilgenfeldt, S., Grossmann, S. and Lohse, D., Nature, 1999, 398, 402.

22. Hilgenfeldt, S., Grossmann, S. and Lohse, D., Phys. Fluids, 1999, 11, 1318

23. Suslick, K. S., Science, 1990, 247, 1439.

24. Flint, E. B. and Suslick, K. S., Science, 1990, 253, 1397.

25. See the articles in Advances in Echo Imaging Using Contrast Enhancement (eds Nanda, N. C. and Schlief, R.), Kluwer Academic Publishers, Dordrecht, 1993.

26. Hilgenfeldt, S., Lohse, D. and Zomack, M., Eur. Phys. J., 1998, B4, 247.

Received 9 November 1999; accepted 18 November 1999 


\title{
Integrating environment, education, and em- ployment for a sustainable society: An HRD agenda for developing countries
}

\author{
A. Raman*, S. Raghu and S. Sreenath
}

Ecological necessities are beginning to drive economic activity. In the developed world, ecological rationality and notions of sustainability have started to prevail over their economic counterparts. One of the outcomes of this realization is the growth of an environmental job market. While identifying some opportunities to meet such a challenge in the new millennium in developing countries, we propose the need to enforce a major shift in the tertiary educational process, emphasizing the progress towards a sustainable society. We argue for an environment-based higher educational effort in developing countries, working towards global solutions taking the regional realities into account and the regional initiatives reflecting global realities.

HISTORICALLY the labour movement perceived the environmental movement as a threat. In a world that is guided purely by economic rationalism, such sentiments from the working class are understandable. However, since the Tblisi Declaration ${ }^{1}$ and the Earth Summit ${ }^{2}$ in Rio de Janeiro, the following statement has gained significance: 'In the long term what is ecologically unreasonable cannot be economical as well as rational. Ecological necessities are beginning to drive economic activity. If we set about ecological modernization in time, we shall improve our chances of conquering tomorrow's markets and improve competitiveness of our economy' ${ }^{3}$. Ecological rationality and notions of sustainability have started to prevail over their economic counterparts. One of the outcomes of this realization is the recognition of an environmental job market. Nowadays careers based on environment have increased substantially, from an amateur, voluntary-body employment sector to a highly-professional area of expertise. The need for professional advice and assistance to business, industry and government has grown immensely. Industry-specific environmental expertise and knowledge have become more relevant and critical in the interpretation of statutes and appropriate application of regulatory information in both private and public sector undertakings in areas such as pollution control and sustainable resource management, with greater demand for appropriately-trained personnel. Better energy utilization,

\footnotetext{
A. Raman is at the University of Sydney (Orange Campus), P.O. Box 883, Orange, NSW 2800, Australia; S. Raghu is at the Faculty of Environmental Sciences, Griffith University, Nathan, QLD 4111, Australia; and S. Sreenath is at the Cranfield Biotechnology Centre, Cranfield University, Bedfordshire MK43 0AL, England.

*For correspondence. (e-mail: raman@oac.usyd. edu.au)
}

CURRENT SCIENCE, VOL. 78, NO. 3, 10 FEBRUARY 2000 recycling, material procurement and management are becoming increasingly relevant today. Clever and sound management skills and good perception of the available state-of-the-art environmental technology also result in efficiency, better budget management, and greater economic benefits.

Career opportunities have grown due to the increased importance and relevance of environmental issues in all sectors of developmental activity. For example, based on the 1992 statistics $^{4}$, in UK alone the number of personnel employed in environment-based sectors was nearly 500,000 . Each country needs to set up its own initiatives to identify the progress and evolution of professional capability especially in the areas of environmental employment and sustainable development.

\section{Sustainable society is a satisfactory society}

Mahatma Gandhi referred to a satisfactory society, long before we ever perceived the present meaning of environment, by saying that the earth can provide for all the needs of humans, but not for their greeds ${ }^{5,6}$. Today we understand what is a sustained practice and how a society needs to function to become sustainable. We also know that a satisfactory society cannot be driven primarily by a profit motive or market forces alone. If these were to dominate our lifestyles, then the inevitable results would be increasing inequality and further deprivation of the afflicted and marginalized. A satisfactory society can have a place for market forces and free enterprise, but some rational and collective decisions need to be made by that society with regard to basic production, distribution, and developmental issues. All of these need to relate to 
morality, justice, quality of life, the social fabric, and environmental sustainability.

Trainer ${ }^{7}$ proposed the following dicta: (a) A satisfactory society cannot have a growth economy, and (b) a satisfactory society cannot have per capita rates of non-renewable resource use in rich countries. From these negative principles, he derived the following positive ideals: (a) Our material living standards must be simple and frugal, and (b) we must develop small, highly self-sufficient settlements and economies. A sustainable society therefore generates out of a co-operative and participatory social movement. Such a social movement dovetails sharing materials and servicing the marginalized, aged, invalid, and disabled. Presently we need a 'new order' of a sustainable economy-driven society that will have a much reduced role for market forces and recognize the need for a zero-growth or steady-state economy. We need to develop systems that will enable us to achieve this goal. The key process that could influence this is education. Educational systems, now more than ever, face the challenge of attending to the needs of a world that is growing in environmental consciousness. We, therefore, exist under desperate pressure to assess the structure of our educational systems and evaluate their suitability towards employment to facilitate the development of a sustainable society.

\section{Environmental education or re-education towards environmental management?}

Why education and why environmental education? Since fundamental disparities exist in the levels of knowledge between the developing and the developed world, at least one answer would be: to enable people to discuss and debate the connections between critical issues and concerns of the times in which they live. Emotional environmental debates vis-à-vis human developmental concerns are presently going on in various parts of the world. Knowledge and clarity imply power. We need to address the question: How to empower people?

The paradox is the enormous level of divergence that exists between knowledge and education and between the developed and the developing countries. This conflict in understanding and translating the seriousness of issues stems from the procedures employed in (a) identification of environmental crises, (b) validation of values placed on environmental issues, and (c) empiricization of the means that are necessary to deal with such issues. An understanding of the bases for environmental issues in developing countries is the first step towards effective action. This is critical because it is the poor, and the powerless who are generally held responsible for environmental problems ${ }^{8}$. Seldom do we realize and acknowledge that the international capital, trade relations and agreements, and technologyintensive activities play fierce roles in affecting the envi- ronment. Unfortunately, through the process of reductionism, the wealthier people manipulate the process to indicate that the rural poor of the developing countries are responsible for the decline of the environment ${ }^{9,10}$. Such a process points to (a) a disinterested examination of the methods used for planning to manage the environment in developing countries and how 'environment' is understood in developing countries, and

(b) recognition of the need for a much better understanding of the relationship between environmental problems in the developing and the developed countries ${ }^{11}$.

Adoption of discarded technologies by the developing countries contribute significantly to environmental issues. For example, the introduced technologies lacked a clear 'fit' with the environment and the people of the humid, tropical Amazonian ecosystems. Amazonian ecosystems are vibrant with (a) staggering biological diversity, (b) highly-specialized processes of nutrient cycling, (c) uncertain succession patterns, and (d) rapid build-up in organic biomass, An environmentally-friendly developmental alternative in such a 'stable' ecosystem would ensure the implementation of one or more of the following alternatives: (a) production of commodity meant for the lo$\mathrm{cal} /$ regional market, (b) validation and implementation of the indigenous knowledge, (c) utilization of local, indigenous technologies, (d) facilitation of easier and informal modes of quick communication, and (e) decisionmaking power resting with the people belonging to that ecosystem ${ }^{12}$. The experience gained through trial and error over several years enabled these people to achieve an extraordinary level of parsimony with Nature. In most of the regions of historically-established civilizations, agricultural practice acts as a rigorous pre-condition to environmental sustainability, although much of it has never been articulated in scientific and measurable terms.

In several parts of the developing world, a significant proportion of knowledge is obtained existentially and experientially, which the developed world labels as traditional knowledge. We prefer to refer to it as traditional wisdom because of the rich experience and collective intelligence that remains buried in them. Very often ideas from traditional wisdom conflict with the scientifically-derived knowledge of the developed world; the former, invariably, is more environmentally friendly and reliable. The pure logic that rationalizes such a notion is that the so-called 'uncivilized', tribal societies have always remained sustainable societies. However, because we remain profoundly conditioned by technological advantages, we need to think that a sustainable society would be unattainable if both these forms of knowledge do not function in tandem. Global solutions need to take regional realities into account, and regional actions must reflect global implications.

Why is a global perspective on the environment not integrated into today's educational system? The barriers to such integration and resultant action are many. The most 
fundamental barrier is that our educational models are based on reductionism. Therefore, we tend to focus more on parts rather than the whole. Consequently, we suffer from the inability to recognize holism and its fundamental importance. The other barriers include lack of excitement and consciousness of local issues among the students, lack of global perspective among teachers, and lack of realistic coverage of world issues by the news media. A general obstacle lies in the tendency of educational efforts to emphasize differences rather than similarities - scarcely conducive to fostering an interdependent one-world ethic ${ }^{13}$. The goals of the International Geosphere-Biosphere Programme (IGBP) highlight such a global perspective by (a) documenting and predicting global changes, (b) observing and improving our understanding of dominant forcing functions, (c) improving our understanding of transient phenomena, and (d) assessing the effects of global changes that would cause large-scale modifications affecting the availability of renewable and non-renewable resources ${ }^{14}$.

The International Global and Atmosphere Chemistry (IGAC) outlines the need for education of tertiary-level students and their educators. We emphasize the urgent need to build a community of scientists required to characterize and examine programmes on global changes. This would attract practising scientists into the general area of global studies and educating researchers in the multidisciplinary framework within which disciplinary studies exist. IGAC strongly recommends this approach and recognizes an immediate need for education of researchers who can work in multidisciplinary modes. Such an approach will especially be crucial for the developing countries. The goals would be to (a) encourage practising scientists to participate and contribute thoughts and solutions to global issues and (b) train students in multidisciplinary aspects of global changes. These require strong motivation in the field of environmental education and more people must be willing to take up environmental management as a profession.

The human species is solely responsible for the overall environmental and ecological uncertainties owing to avaricious technology, and the hastened events of global environmental change. Those that help in sustaining human life-agriculture, manufacturing, transportation ultimately contribute to one or many of the major environmental issues, such as global warming ${ }^{15}$. We need to realize that much of the splendid science currently underway depends not only on the relative maturity of the physical and biological sciences but also on interdisciplinary scientific activities. The latter is the quintessence of heterogeneous expertise on critical environmental problems at a global scale and contributes to a strong conceptual framework. Without such an institutionalization scientific progress on global environmental change would be substantially slow. There are, of course, established interdisciplinary fields in the social sciences some especially relevant to global environmental changes. Demography is one example, and Urban Planning and Management is another.

\section{International environmental education and experience}

The key understanding here will be to accept international need and dependence, since environmental problems are either multinational or global, and they can be resolved by only determined international collaboration ${ }^{16}$. In the European tertiary educational institutions, environmental education is undergoing expansion and change. A project at the University of Reading provides a means for producing modular INSET (in-service training) materials to meet the needs of teachers for their professional development in environmental education, whatever be their subject expertise ${ }^{17}$. This model considers biological science is more important than other sciences in environmental education. In Austria, vocational schools and Advanced Academics of Agriculture impart countryside management knowledge to young farmers. An analysis of curricula and teaching-learning programmes using a specially-developed standardized text evaluation method and additional interviews with specialized instructors shows far-reaching defects. One of the solutions proposed is a more landscape-oriented syllabus ${ }^{18}$.

Science education in the US is undergoing reform, providing an excellent opportunity to use sustainable agriculture as the basic theme in teaching science ${ }^{19}$. The following questions are gaining high priority: When is the right time to start imparting environmental education, and at what level? Should the world have a common environmental education framework apart from education on local issues? An understanding of human population growth, consumption patterns, and their effects on the environment, is essential for proper conservation efforts ${ }^{20}$. Education on population and environmental issues will improve if the linkages among population size, consumption, and environmental quality are examined and discussed within classrooms.

Awareness education programmes should be encouraged, especially in the developing countries which still control great portions of the earth's biodiversity. Environmental education programmes trailed in Brazil have been evaluated. The programmes contributed informally to the conservation of the Black Lion National Park. Experience from the Tamarin Environmental Education Programme suggests that similar programmes in Nature Parks and Reserves can be effective and should be established more widely ${ }^{21}$. Should the awareness programmes aim at developing countries alone? If yes, would it not again be a Catch-22 situation in the problem of North-South divide?

\section{Environmental management - Integrating soci-}




\section{ety and education}

Environmental management practice in most of the developing countries, in general, has been an unrefined adoption of models from the developed nations. This is undesirable because the economic situation in developed countries is very different from that existing in the developing countries. For example, the developed countries invariably have a food grain surplus rather than any deficit. Eventually, their plans and environment management models keep agriculture contracting rather than increasing productivity. Hence, it would be more appropriate for the developing countries to relate to the identified objectives of the World Conservation Strategy ${ }^{22}-$ (a) maintenance of essential ecological processes, (b) preservation of genetic diversity, and (c) sustainable utilization. This also implies that the participants in these efforts have clear and definite roles to perform in order to achieve a sustainable society. The general public should be able to freely and effectively obtain technical information on local or national concerns. The media should publicize 'constructive and healthy' stories, appropriately time the communication, and present technical information in simple and effective modes. Political leaders must have excellent briefing skills, ability to appeal to self-interest, and target those with influence. Industry should be able to instill an 'environmental culture' within management structures and encourage a totalitarian approach to environmental management. The non-governmental interest groups (NGOs) should play a supportive and positive role by forming focus groups.

Given that no universal model of education for employment refers to achieving a sustainable society in clear terms, we offer a framework (Figure 1) that addresses the educational approach needed to realize such a demand. This framework, of course, is neither absolute nor definitive, but it provides details of how each trainee/participant can/will perform, and thus enable the society to become sustainable, following a disciplined work ethic. The framework includes levels that explain the title, role, academic qualification (a relative correlate of the attained education), and examples. We now deal with examples from levels 1 and 2 and explain our view. We are aware that a potential overlap exists in some of the roles we have identified and some of the functions described could be idealistic. Nonetheless, our perception is that only such a division of labour will enable the achievement of a sustainable society.

\section{Environmental educators}

The pedagogy for Environmental science is an art in itself. Educators delving in environmental science need (a) to possess an up-to-date knowledge, and (b) be able to evaluate critically the notion(s) of development in the context of a sustainable society ${ }^{23}$. A critical component of learning and imparting environmental education is the acknowledgement of indigenous wisdom. The imminent skill of an environmental educator lies in his/her ability to synthesize scientifically-derived knowledge and existentiallyderived indigenous knowledge. He/she must have excellent communication skills and be able to minimize (or eliminate) personal bias consciously while communicating with target audience. Learning needs could necessarily vary with the origins and backgrounds of the learners, and therefore, the educators must be quick enough to pick on such specific needs and cater to those learners in the most effective way.

\section{Environmental scientists}

The primary role of the scientists will be to develop the theory relative to any one or more environmental issues. While they can work in their own specific interest area, they must be conscious of the fact that their work integrates with the objective of contributing to a bigger picture, by facilitating the development of a sustainable society. Another critical role the scientists must play will be to test and try to validate beliefs and practices of indigenous people, since much knowledge has been accumulated over several centuries through simple processes of trial and error.

\section{Environmental engineers}

The role of human resource is to translate the theory developed by the scientists into practical work through plans and programmes. It is critical that these engineers (sensu lato) too never lose sight of the bigger picture. Application of the sustainability theory, in conjunction with the creative skills of engineers will enable the achievement of a sustainable society. When we examine engineering education in the context of environment, we find that it is at crossroads: will it continue in the existing paradigm or will it change direction along the path marked 'the liberated and civilized engineer'? People do matter, but their attitudes to the natural world and to each other matter most of all ${ }^{24}$.

\section{Environmental managers}

A vast majority of the nations located in the wet tropics of the earth are essentially developing countries with very large populations. For survival, people here extract the already-exhausted natural-resource reserves. Environmental managers perform a vital role in balancing such conflicts and resolving them. They should possess the 


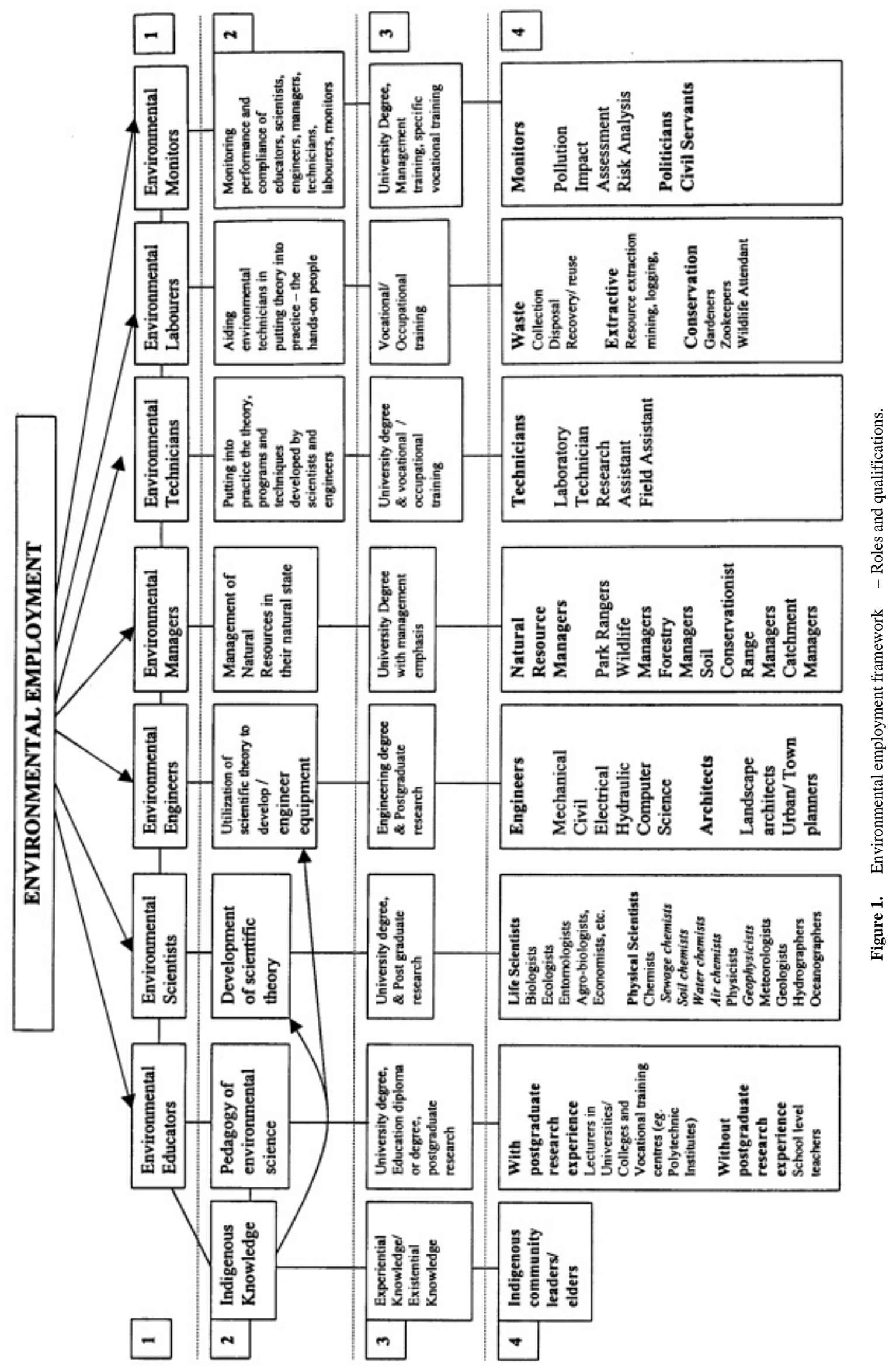


necessary knowledge and ability to translate and apply principles of validated indigenous knowledge since much of the tested behaviour of the indigenous people underscores their wisdom of managing the environment and prudent utilization and not exploitation of natural resources ${ }^{25}$.

\section{Environmental technicians/labourers}

These are the people who operate at the implementation levels. Although they essentially work at the psycho-motor domain, they perform a significant function by translating the principles into action. They too need to have a clear understanding of the bigger picture, to ultimately achieve their goal. Besides offering appropriate help and guidance, respect for their significant role needs to be acknowledged. University courses must integrate environmental education which will emphasize cleaner production taking the current and future environmental problems into consideration ${ }^{26}$.

\section{Environmental monitors}

These hold custody of the notion of development of a sustainable society. They cautiously monitor performance and compliance of the other participants as well as their own, in achieving their goal. Politicians and civil servants, for example, fall under this category. They must possess the ability to think clearly while integrating several issues and acquaint themselves with both success and failure and be able to look into the future with a clear vision. They need to understand in very clear terms that their role is not superior to any other participant in the project. They need to bear in mind that they remain answerable and accountable to the people who elected/nominated them for the positions they hold.

We wish to clarify here that the prefix 'environmental' is not used as a superfluous term, simply embellishing the existing professions. That prefix is the call for a fundamental environmental ethic to guide and govern our actions. It is the realization of this ethic and the sense of commitment that links the definitive roles we need to play within a proposed framework to achieve a satisfactory and sustainable society.

\section{Role of tertiary educational institutions}

All university students should be environmentally educated and leaders in all walks of life, be made environmentally aware. The issue here is how to fit in the environment into the curriculum. The eclectic nature of environmental problems demands that environmental specialists also need to be broadly educated ${ }^{27}$.

The need for a new order of professionalism with deep commitment to environmental matters is imperative. Qualities of such a professionalism generate out of the thinking that reflects social equity. New initiatives in environmental education are necessary in the form of graduate and professional academic programmes clearly emphasizing the practice and the growing necessity of a multidisciplinary focus. We present here an academic degree model:

- The model generates out of Fritjof Capra's 'ecological world view' which fundamentally enables the linking of the individual with the whole. It will enliven at least the following two tenets of Capra ${ }^{28,29}$.

(i) shift from the part to the whole,

(ii) shift from truth to approximate descriptions.

- The other critical requirement is scientific competence. By this we refer to the capability of rationalizing and evaluating one's own thinking and work as against those of others.

- The proposed undergraduate curriculum will build itself on three core constituents

(i) Environmental Science and Engineering,

(ii) Principles and Ethics of Business and Management,

(iii) National and International Public Policy.

In addition to these, a definite focus towards some of the more-immediate critical issues, such as environmental audit, sustainable development, mass media, occupational environmentalism, medical and engineering professionals needs to be perceived with greater emphasis. We also believe that a periodic environmental round-table, as proposed by Lynch and Hutchinson $^{30}$, will be critical, involving academics, industrialists, government officials, and representatives of the general public, to discuss environmental issues. Such a round-table will provide the necessary overview for professional approach, clarity of purpose, and vision.

\section{Conclusion}

Sustainability is the bedrock for a better future of human existence. Hence, it is vital to integrate concepts and practice of environmentalism to facilitate a sustainable society. Our ideas, described earlier are an urgent plea for an integrated and designed approach, linking human resources and their potentials. Towards that end, we propose here the need to identify a major shift in the tertiary educational processes underscoring the importance of environmental management towards a sustainable society. Because the job market always pre-conditions the players, we have attempted to integrate environment-related educational efforts with job opportunities. Nevertheless, the key issue is to offer a conceptual framework. This outline we think, is critical for educational planners and administrators in developing countries to align on two critical dimensions (a) efficiency in education and (b) efficiency in resource use. Each nation will have its own characteristics and planning needs to be developed based on such a blueprint. Some aspects of this blueprint may appear 
idealistic and may not truly reflect true situations in every possible circumstance; but we earnestly hope that it will stimulate new thoughts, foreshadowing new debates and new plans, and realizations to achieve sustainable societies in developing nations.

1. UNESCO-UNEP, Connect, 1978, 3, 1-8.

2. UNESCO, Connect, 1992, 17, 1-7.

3. Gorz, A., Capitalism, Socialism, Ecology (Tr. by C. Turner), Verso, London, 1994, pp. 148.

4. Environmental Constancy in Britain, A Market Analysis, Environmental Data Services, United Kingdom, 1992.

5. Joshi, N. C., India Perspect., 1999, 12, 30.

6. Raman, A., Bull. Ecol. Soc. Am., 1992, 73, 160.

7. Trainer, T., Saving the Environment, UNSW Press, Sydney, 1998, pp. 62.

8. Gadgil, M. and Guha, R., Ecology and Equity: The Use and Abuse of Nature in Contemporary India, Rouletge, London, 1995 , pp. 213.

9. Guha, R., Environ. Ethics, 1989, 11, 71-83.

10. Guha, R., Ecologist, 1997, 27, 14-20.

11. Redclift, M., In Education, Ecology, and Development: The Case for an Education Network (eds Lacey, C. and Williams, R.), World Wildlife Fund and Kogan Page, London, 1987, pp. 2138.

12. Norgaard, R., Am. J. Agric. Econ., 1984, 66, 874-878.

13. Strapp, W. B. and Polunin, N., Environ. Conserv., 1991, 18, $13-18$.

14. IGBP, Special Committee Report for discussion at the 1 st meeting of the Scientific Advisory Council for the IGBP, Stock- holm,

Sweden, October, 1988.

15. Berk, R. A., Global Environ. Change, 1991, 1, 83-96.

16. Cawsey, D. C., Marine Pollut. Bull., 1994, 29, 584-588.

17. Gayford, C., J. Biol. Educ., 1994, 28, 284-290.

18. Penker, M. and Wytrzens H. K., Bodenkultur, 1996, 47, 119131.

19. Henderson, S., J. Sust. Agric., 1992, 3,153-161.

20. Holl, K. D., Daily, G. C., Daily, S. C., Ehrlich, P. R. and Bassin, S., Environ. Conserv., 1999, 26, 66-74.

21. Padua, S. M., Environ. Conserv., 1994, 21, 145-151.

22. IUCN, World Conservation Strategy, International Union for the Conservation of Nature, Gland, Switzerland, 1980.

23. Fien, J., Connect, 1996, 21, 1-3.

24. Duffell, R., J. Prof. Issues Eng. Educ. Pract., 1998, 124, 78-90.

25. Raman, A., Bull. Ecol. Soc. Am., 1998, 79, 131.

26. Dodner, G., Huisingh, D. and Jorgensen, M., Nat. Resour., 1992, 28, 17-25.

27. Kupchella, C. E., ACS Symp. Ser., 1992, 483, 473-480.

28. Capra, F., The Web of Life, The New Scientific Understanding of Living Systems, Anchor Books, New York, 1996.

29. Kafatos, M. and Nadeau, R., in The Conscious Universe - Part and Whole in Modern Physical Theory, Springer Verlag, New York, 1990, pp. 182-184.

30. Lynch, D. R. and Hutchinson, C. E., Proc. Nat. Acad. Sci. USA, 1992, 89, 864-867.

ACKNOWLEDGEMENT. We thank Kees Hulsman, Griffith University, Australia; Kerry Cochrane and Lindy Eggleston, The University of Sydney - Orange Campus, Australia; and David Weston, Cranfield University, England for constructive comments.

Received 14 September 1999; accepted 13 December 1999 